\title{
HUBUNGAN ANTARA PES PLANUS DENGAN KESEIMBANGAN DINAMIS PADA MURID MI NURUL KARIM COLOMADU
}

\author{
Agus Setyo Nugroho, Fadhila Firma Nurulita
}

Poltekkes Kemenkes Surakarta Jurusan Ortotik Prostetik

\begin{abstract}
Background: The ability to balance children at the age of development is very important to be reviewed, both in terms of balance sitting, standing, and walking. One of the factors that can cause balance disorders in children is musculoskeletal disorders in the form of deformity of the soles of the feet. The shape of the human foot is divided into three types, namely normal foot, pes planus and cavus foot according to the arcus structure or arches on the soles of the feet. Normally the arch is formed from the first 5 years with a 2-6 year age range. The critical period for arch formation is the age of 6 years (Campbell, 2012). In the early age of school there were $28 \%$ - 35\% of children experiencing deformity of pes planus, $80 \%$ of which were categorized as "moderate". Methods: This research is a type of correlational research with a cross sectional design which aims to determine the relationship between pes planus and the dynamic balance in MI Nurul Karim Colomadu's students. The subjects used were grade 1-5 students with the condition of pes planus at MI Nurul Karim Colomadu, who had determined the inclusion and exclusion criteria. The number of subjects was 40 people with male and female sex from a total population of 92 people. Result: Using the Spearman Correlation Test Based on the table above, it is known that the value of $p=0.869$ shows that there is no significant relationship between sex and dynamic balance. The value of $r=0.27$ indicates the strength of the weak correlation. While the value of $p=0,000$ shows there is a significant relationship between pes planus and dynamic balance. The value of $r=-0,599$ shows the strength of the medium correlation. Conclusion: One conclusion is 1 . The prevalence of pes planus in girls is greater than that of boys, ie 16 boys and 24 girls have Pes Planus.
\end{abstract}

Keywords: Pes Planus, Dynamic Balance

\section{PENDAHULUAN}

Kemampuan keseimbangan anak pada usia perkembangan sangat penting untuk ditinjau, baik dari segi keseimbangan duduk, berdiri, dan saat berjalan. Keseimbangan merupakan salah satu bagian atau hal yang paling penting dalam beraktifitas dimana setiap orang memerlukan keseimbangan dalam mempertahankan posisi tubuhnya dalam bergerak atau beraktifitas.
Keseimbangan merupakan kemampuan memelihara tubuh dalam pusat massa tubuh (center of mass) terhadap bidang tumpu (base of support) untuk melawan gravitasi (center of gravity) dipengaruhi oleh proses sensorik atau sistem saraf, motorik atau muskuloskeletal, dan efek luar (Bacolinni, 2013).

Salah satu faktor yang dapat menyebabkan gangguan keseimbangan pada anak yaitu gangguan 
muskuloskeletal berupa kelainan bentuk telapak kaki. Bentuk telapak kaki manusia terbagi menjadi tiga jenis yaitu normal foot, pes planus dan cavus foot sesuai struktur arcus pedis atau lengkungan pada telapak kaki. Lengkungan ini juga berfungsi untuk meningkatkan kecepatan dan kelincahan selama berjalan serta memberikan stabilisasi dan fleksibilisasi

Pada masa tumbuh kembang anak, sebagian besar telapak kaki anak mengalami penebalan jaringan lunak pada sisi dalamnya (medial), keadaan ini akan menurun seiring dengan masa pertumbuhannya. Salah satu kelainan /gangguan yang dapat menyebabkan hambatan berjalan adalah pes planus. Keadaan ini disebabkan oleh adanya kelemahan struktur yang menyokong arkus longitudinal pedis, yaitu (1) otot otot pendek pada kaki, (2) ligamentum plantaris, (3) tendon tibialis anterior dan posterior

Pes Planus merupakan kondisi orthopedik klinis dimana arkus longitudinal medial tidak tampak sejak lahir dan area tersebut tertimbun jaringan lemak. Normalnya arkus terbentuk dari 5 tahun pertama dengan rentang usia 2-6 tahun. Masa kritis untuk pembentukan arkus tersebut adalah usia 6 tahun (Campbell, 2012). Dalam masa usia awal sekolah terdapat $28 \%-35 \%$ anak mengalami deformitas pes planus, $80 \%$ diantaranya dikategorikan "sedang" Setelah lahir, bentuk arkus datar atau pes planus derajat satu sebesar $80 \%$ secara bertahap berubah menjadi lengkung normal. Arkus pes planus derajat tiga, frekuensinya tetap pada setiap strata umur 0-18 tahun. Arkus pes planus derajat dua, frekuensinya menurun sebagian. Hal itu berlaku pada laki-laki maupun perempuan. Dengan demikian, dapat disimpulkan bahwa sekitar 20\% populasi, arcus pedisnya belum mencapai bentuk normal dan 0,6-1,2\% mengalami pertumbuhan berlebih atau cavus foot (Idris, 2010).

\section{METODE PENELITIAN}

Dari penelitian yang dilakukan oleh Roohi et. al (2013) dan Dabholkar et. al (2012) bahwa ada perbedaan keseimbangan statis dan dinamis serta kelincahan yang signifikan pada anak pes planus dan kaki normal. Dalam penelitian yang dilakukan oleh Ali dan Mohamed (2011) terdapat perbedaan keseimbangan dinamis antar kelompok pes planus dengan kelompok normal foot. Hal ini dapat terjadi pada segala usia dan dapat terjadi pada satu atau kedua kaki. Sebuah survei terhadap 297 anak sekolah di Allahabad, India mengungkapkan bahwa 40,32\% anak di bawah 5 tahun, 22,15\% anak-anak antara 5 sampai 10 tahun, dan $15,48 \%$ anak berusia lebih dari 10 tahun menderita pes planus bilateral (Sharma et al., 2005). Dari observasi pendahuluan yang dilakukan pada 93 murid MI Nurul Karim Colomadu usia 5-7 tahun ditemukan bahwa lebih dari 50\% anak mempunyai kaki pes planus. Dengan melihat fenomena di atas, membuat peneliti tertarik untuk melakukan penelitian mengenai hubungan antara pes planus dengan keseimbangan dinamis.

\section{HASIL PENELITIAN}

Tabel 1. Distribusi Subjek Penelitian berdasarkan Jenis Kelamin

\begin{tabular}{ccc}
\hline $\begin{array}{c}\text { Jenis } \\
\text { Kelamin }\end{array}$ & Frekuensi & $\begin{array}{c}\text { Persentase } \\
(\boldsymbol{\%})\end{array}$ \\
\hline Laki-laki & 16 & 40 \\
Perempuan & 24 & 60 \\
\hline \multicolumn{1}{c}{ Total } & $\mathbf{4 0}$ & $\mathbf{1 0 0}$ \\
\hline
\end{tabular}




\begin{abstract}
Berdasarkan tabel 1 Jumlah subjek laki-laki lebih sedikit dibandingkan subjek perempuan, dimana jumlah laki-laki sebanyak 16 orang (40\%) dan perempuan sebanyak 24 orang $(60 \%)$.
\end{abstract}

Tabel 2. Distribusi Subjek Penelitian berdasarkan usia

\begin{tabular}{ccc}
\hline Usia & Frekuensi & Persentase(\%) \\
\hline 6 & 3 & 7,5 \\
7 & 7 & 17,5 \\
8 & 6 & 15 \\
9 & 15 & 37,5 \\
10 & 4 & 10 \\
11 & 4 & 10 \\
12 & 1 & 2,5 \\
\hline Total & $\mathbf{4 0}$ & $\mathbf{1 0 0}$ \\
\hline \multicolumn{4}{c}{ Berdasarkan tabel 2} \\
subjek berusia 6 tahun sejumlah 3 orang \\
$7,5 \%$ ), jumlah subjek berusia 7 tahun \\
sejumlah 7 orang ( 17,5\%), jumlah subjek \\
berusia 8 tahun sejumlah 6 orang (15\%), \\
jumlah subjek berusia 9 tahun sejumlah \\
15 orang (37,5\%), jumlah subjek berusia \\
10 tahun sejumlah 4 orang (10\%), jumlah \\
subjek berusia 11 tahun sejumlah 4 orang \\
(10\%), jumlah subjek berusia 12 tahun \\
sejumalah 1 orang (2,5\%)
\end{tabular}

Tabel 3. Distribusi Subjek Penelitian berdasarkan Type pes planus

\begin{tabular}{|c|c|c|}
\hline $\begin{array}{l}\text { Type Pes } \\
\text { Planus }\end{array}$ & Frekuensi & Persentase (\%) \\
\hline Normal & 0 & 0 \\
\hline Grade 1 & 3 & 7,5 \\
\hline Grade 2 & 27 & 67,5 \\
\hline Grade 3 & 10 & 25 \\
\hline Total & 40 & 100 \\
\hline
\end{tabular}

subjek yang mengalami pes planus grade 1 sejumlah 3 orang $(7,5 \%)$, jumlah subjek yang mengalami pes planus grade 2 sejumlah 27 orang $(67,5 \%)$ dan subjek yang mengalami pes planus grade 3 sejumlah 10 orang $(25 \%)$
Tabel 4. Distribusi Subjek Penelitian berdasarkan skor tes keseimbangan

\begin{tabular}{|c|c|c|}
\hline Skor tes & Frekuensi & Persentase (\%) \\
\hline Baik & 7 & 17,5 \\
\hline Sangat Baik & 33 & 82,5 \\
\hline Total & 40 & 100 \\
\hline
\end{tabular}
subjek yang mendapatkan skor 4 dengan kategori baik sejumlah 7 orang $(17,5 \%)$, jumlah subjek yang mendapatkan skor 5 dengan kategori sangat baik sejumlah 33 orang $(82,5 \%)$

Tabel 5. Distribusi Pes planus berdasarkan Jenis Kelamin

\begin{tabular}{ll|lr|lr|rr|c}
\hline $\begin{array}{l}\text { Jenis } \\
\text { Kelamin }\end{array}$ & \multicolumn{9}{c}{$\begin{array}{c}\text { Pes Planús } \\
\text { Grade II }\end{array}$} & \multicolumn{3}{c}{ Grade III } & \multicolumn{2}{c}{ Total } \\
\hline & $\mathbf{n}$ & $\%$ & $\mathbf{n}$ & $\mathbf{\%}$ & $\mathbf{n}$ & $\%$ & $\mathbf{n}$ & $\%$ \\
Laki-laki & 2 & 5 & 9 & 22,5 & 5 & 12,5 & 16 & 40 \\
Perempuan & 1 & 2,5 & 18 & 45,5 & 5 & 12,5 & 24 & 60 \\
\hline Total & $\mathbf{3}$ & $\mathbf{7 , 5}$ & $\mathbf{2 7}$ & $\mathbf{6 7 , 5}$ & $\mathbf{1 0}$ & $\mathbf{2 5}$ & $\mathbf{4 0}$ & $\mathbf{1 0 0}$ \\
\hline
\end{tabular}

Berdasarkan hasil pemeriksaan arkus pedis diketahui bahwa dari 40 orang subjek penelitian terdapat 3 orang memiliki pes planus grade I (ringan), 27 orang memiliki pes planumsgrade II (sedang), dan 10 orang memiliki pes planusgrade III (berat). Subjek laki-laki yang memiliki pes planusyaitu sebanyak 16 orang dengan pes planusgrade I sebanyak 2 orang (5\%), pes planusgrade II sebanyak 9 orang (22,5\%), dan pes planusgrade III sebanyak 5 orang $(12,5 \%)$. Subjek perempuan yang memiliki pes planusyaitu sebanyak 24 orang dengan pes planusgrade I sebanyak 1 orang $(2,5 \%)$, pes planus grade II sebanyak 18 orang $(45,5 \%)$, dan pes planus grade III sebanyak 5 orang $(12,5 \%)$

Tabel 6. Korelasi Tiap Variabel dengan Keseimbangan Dinamis

\begin{tabular}{lccc}
\hline Variabel & $\mathbf{P}$ & $\mathbf{R}$ & $\mathbf{N}$ \\
\hline Jenis Kelamin & $0,869^{*}$ & $0,27^{*}$ & $40^{*}$
\end{tabular}


\begin{tabular}{cccc} 
Pes palnus & $0,000 *$ & $0,599 *$ & $40 *$ \\
\hline$*=$ Uji Korelasi Spearman \\
Berdasarkan table 6 di atas
\end{tabular} diketahui bahwa nilai $\mathrm{p}=0,869$ menunjukkan tidak terdapat hubungan yang bermakna antara jenis kelamin dengan keseimbangan dinamis. Nilai $r=$ 0,27 menunjukkan kekuatan korelasi lemah. Sedangkan nilai $\mathrm{p}=0,000$ menunjukkan terdapat hubungan yang bermakna antara pes planus dengan keseimbangan dinamis. Nilai $r=-0,599$ menunjukkan kekuatan korelasi sedang

\section{PEMBAHASAN}

Hubungan antara pes planus dengan keseimbangan dinamis pada murid MI Nurul Karim Colomadu

Hasil penelitian menunjukkan bahwa terdapat hubungan yang bermakna antara jenis kelamin dengan keseimbangan dinamis. Nilai $r=0,27$ menunjukkan kekuatan korelasi lemah. Sedangkan nilai $\mathrm{p}=0,000$ menunjukkan terdapat hubungan yang bermakna antara pes planus dengan keseimbangan dinamis. Nilai $r=-0,599$ menunjukkan kekuatan korelasi sedang

Dari hasil penelitian ini ditemukan bahwa terdapat hubungan yang bermakna antara pes planus dengan keseimbangan dinamis

Adapun pada penelitian ini diperoleh hubungan antara pes planus dengan keseimbangan dinamis $(\mathrm{p}<0,05)$ dengan nilai $r=-0,599$. Nilai tersebut menunjukkan semakin tinggi grade pes planus maka semakin rendah tingkat keseimbangan dinamis. Hal yang serupa juga ditemukan pada penelitian yang dilakukan oleh Ali dan Mohamed pada tahun 2011, yang menyatakan bahwa ada hubungan yang signifikan antara pes planus dengan keseimbangan dinamis $(\mathrm{p}$
$=0,004)$. Menurut Benedetti et.al (2011) sebanyak $75,3 \%$ anak dengan pes planus tidak mampu untuk berdiri satu kaki dengan waktu yang lama karena ketidakstabilan sendi subtalar dan adanya posisi eversi dari sendi subtalar yang menghambat keseimbangan selama berdiri satu kaki. Penelitian lain dilakukan oleh Roohi et. al (2013) dan Dabholkar et. al (2012) bahwa ada perbedaan keseimbangan statis dan dinamis serta kelincahan yang signifikan pada anak pes planus dan kaki normal.

Penelitian ini dilakukan pada anak laki-laki maupun perempuan di MI Nurul Karim pada usia (6 - 12 tahun ). Anak laki-laki yang memiliki pes planus sebanyak 16 orang (40\%) dan anak perempuan sebanyak 24 orang $(60 \%)$. Sehingga dari penelitian ini dapat dilihat jumlah anak perempuan yang memiliki pes planus lebih banyak dibandingkan anak laki - laki. Hal ini tidak sesuai dengan hasil penelitian yang dilakukan sebelumnya oleh Martin Pfeiffer., et al. pada tahun 2006 yang mendapatkan bahwa anak laki-laki memiliki resiko yang lebih besar untuk mengalami pes planus daripada anak perempuan. Prevalensi pes planus pada anak laki- laki sebesar $52 \%$ dan pada perempuan sebesar $36 \%$. Lebih umumnya ditemukan kondisi pes planus pada laki-laki dibandingkan perempuan diduga karena adanya perbedaan anatomis tubuh, dimana rearfoot angle (nilai rata-rata valgus) pada anak laki-laki lebih besar dibandingkan pada anak perempuan (Pfeiffer, et al., 2006). Selain itu, menurut penelitian diketahui bahwa sudut (derajat) arkus lateral dan medial pada perempuan lebih besar dibandingkan pada laki-laki (Fukano dan Fukubayashi, 2011). 
Pada penelitian ini diperoleh hasil yaitu tidak ada hubungan bermakna antara jenis kelamin dengan keseimbangan dinamis $(\mathrm{p}>0,05)$ pada anak laki-laki maupun perempuan. Hal ini berbeda dengan hasil penelitian sebelumnya yang dilakukan oleh Permana pada tahun 2013 yang menyatakan ada hubungan antara usia dengan keseimbangan dinamis yang ditinjau dari jenis kelamin. Perbedaan hasil dari kedua penelitian ini disebabkan karena responden penelitian hanya mencakup usia anak yaitu 6 sampai 12 tahun.

Beberapa literatur menyebutkan bahwa anak dengan kondisi kaki datar memiliki keseimbangan yang jelek dibandingkan dengan anak yang memiliki arkus kaki normal ( Hsing, 2007; Pryce, 2006; Meidy, 2007; Abdurrahman,2003; Ferry,2006). Namun ada pula yang berpendapat fungsi keseimbangan tergantung pada fungsi mekanisme dari semisirkular kanal, kinesthetic sensation pada otot, tendon, dan sendi, serta persepsi visual ketika tubuh melakukan gerakan, dan kemampuan mengkoordinasikan ketiga sumber rangsangan (Lendra, 2007).

Kondisi pes planus bersifat progresif artinya jika tidak ditangani dengan baik maka kondisi kaki tersebut akan bertambah buruk dengan terjadinya deformitas valgus dan akan mengarah pada kondisi kaki planus. Dari penelitian ini ditemukan bahwa semakin tinggi grade pes planus maka kemampuan keseimbangan dinamis anak semakin rendah. Keseimbangan merupakan kemampuan yang penting dimana digunakan dalam aktifitas kita seharihari, seperti berjalan, berdiri dan berlari. Rendahnya kemampuan keseimbangan pada anak dapat mengakibatkan anak rentan jatuh dan mengalami hambatan saat berjalan. Hambatan berjalan pada anak dalam masa tumbuh kembang akan mempengaruhi pemenuhan kebutuhan anak, dimulai dari gangguan bergerak aktif, bermain, dan aktivitas sehari-hari (ADL) sampai berdampak menurunnya produktivitas anak. Anak menjadi tidak aktif, tidak bergairah, lesu dan malas. Jika adanya penurunan fungsi keseimbangan juga akan menyebabkan menurunnya kontrol postur, menurunnya alignment tubuh, monitoring kepala, kontrol reflek gerak mata serta dalam mengarahkan gerakan. Maka dari itu peran ortotik prostetik pada kasus pes planus diperlukan guna memberikan alat bantu untuk mengkoreksi dari aligment yang salah akibat dari pes planus.

\section{KESIMPULAN DAN SARAN}

Kesimpulan:

1. Prevalensi pes planus pada anak perempuan lebih besar daripada anak laki kali yaitu 16 anak laki-laki dan 24 anak perempuan memiliki Pes Planus.

2. Ada hubungan yang bermakna antara pes planus dengan keseimbangan dinamis pada murid MI Nurul Karim colomadu. Semakin tinggi grade pes planus maka semakin rendah tingkat keseimbangan dinamis anak.

Saran:

a. Subjek penelitian yang mengalami pes planus sebaiknya menggunakan alas kaki korektif dan melakukan latihan-latihan seperti stretching, strengthening dan latihan berjinjit untuk membantu membentuk lengkungan telapak kaki. 
b. Subjek penelitian yang tetap mengalami pes planus sebaiknya melakukan konsultasi dengan ortotik prostetik dan atau dokter untuk mendapatkan penanganan yang sesuai agar mencegah deformitas permanen

c. Subjek penelitian yang mengalami kemampuan keseimbangan dinamis rendah dapat dilatih terus keseimbangannya dengan berjalan di atas papan titian ataupun berjalan mengikuti satu garis lurus.

d. Diperlukan penelitian lebih lanjut dengan instrumen yang lebih tepat mengingat bahwa masih kurangnya data serta penelitian mengenai masalah ini, khusunya di Indonesia.

\section{DAFTAR RUJUKAN}

Abrahamova D \& Hlavacka F. 2008. Age-Related Changes of Human Balance during Quiet Stance: Slovakia . Physiological Research.

Ali, Mohamed Ibrahim. 2011. Dynamic Postural Balance in Subjects with and without Pes planus[Skripsi]. Cairo : Department of Basic Sciences of Physical Therapy, Faculty of Physical Therapy, Cairo University.

Anzai et,. al. 2014. Effects of Foot Arch Structure on Postural Stability. Division of Healthcare Informatics, Tokyo Healthcare University, Tokyo, Japan.

Aston.J.N (1983); Traumatologik Dan Ortopedik, EGC,Jakarta, hal $196-199$.

Avenue Davie, "10 Common Causes of Foot Pain", Carolina Foot Care Associates, PLLC Medical and Surgical Treatment of the Foot, http://www.carolinafootcare.com/ diakses 15 april 2016.

Baccolini G. 2013. Using Balance Training to Improve the Performance of Youth Basketball Players. Sport Sci Health. Volume 9. Nomor 1. 37-42.

Bachtiar, Farahdina. 2012. Gambaran Arkus Pedis pada Mahasiswa Ortotik prostetik. Makassar: Prodi S1 Ortotik prostetik, Fakultas Kedokteran, Universitas Hasanuddin.

Benedetti M G, Francesco Ceccarelli, Lisa Berti, Deianira Luciani, Fabio Catani, Marco Boschi, Sandro Giannini. 2011. Diagnosis of Flexibel Pes planusin children: A Systematic Clinical Approach. Volume 34. Nomor 2. 94-99.

Brown, S.P., Miller, W.C., \& Eason, J.M, 2006. Neuroanatomy and Neuromuscular Control of Movement. Exercise physiology: Basis of human movement in health and disease. Philadephia: Lippincott Williams \& Wilkins. 217-246.

Campbell, S.K., 2000; The Child's Development of Functional Movement dalam Campbell, S.K. (ed); Physical Theories for Children, Second Edition, W.B. Saunders, Philadelphia, hal. 3-28.

Chang, Y.W. 2009. Postural Responses in Various Bases of Support and Visual United Stated: Lippincott Williams and Wilkins.

Cook, S. 2001. Motor Control: Theory and Practical Applications. Philadelphia: Lippincott Williams \& Wilkins.

Dabholkar A, Ankita Shah, SujataYardi. 2012. Comparison of 
DynamicBalance Between Flat Feet and Normal Individuals Using Star Excursion Balance Test. Indian Journal of Physiotherapy \& Occupational Therapy of International Journal. Volume 6. Nomor 3. 27-31.

Dahlan Sopiyudin,M. 2011. Statistikuntuk Kedokteran danKesehatan: Deskriptif, Bivariat, dan Multivariat. Edisi 5. Jakarta : Salemba Medika.

Delitto A, 2003. "The Link Between Balance Confidence and Falling". Physical Therapy Research That Benefits You, American Physical Therapy Association.

Fatmah dan Ruhayati. 2011. Gizi Kebugaran dan Olahraga. Bandung: Lubuk Agung.

Franco, Abby Herzog. 1987. Pes Cavus and Pes Planus: Analyses and Treatment.

Journal of The American Physical Therapy Association.

Giovanni, Christopher Di dan Greishberg, Justin. 2007. Foot and Ankle: Core Knowledge in Orthopaedics. Elsevier Mosby.

Harris, Edwin J., et al. 2004. Diagnosis and Treatment of Pediatric Flat foot. The Journal of Foot \& Ankle Surgery, Volume 43, No.6, November/Desember. American College of Foot and Ankle Surgeons.

Hendrickson Gail, "Flat Feet, Your Health Encyclopedia", http://www.healthopedia.com/ 2006, Patient Marketing Group, Inc. accessed Apri 122016

Horak, F. B. 2006. Mechanistic And Physiological Aspects Postural Orientation And Equilibrium:
What Do We Need To Know About Neural Control Of Balance To Prevent Falls?. Oxford University Press on behalf of the British Geriatrics Society.

Huxham FE, Goldie PA and Patla AE, 2001. "Theoretical considerations inbalance Assessment".

Australian Journal of Physiotherapy

Idris, Ferial Hadipoetro. 2010. Filogeni dan Ontogeni Lengkung Kaki Manusia, Majalah Kedokteran Indonesia, Vol: 60, Nomor: 2, Februari 2010. Jakarta: Departemen Kedokteran Fisik dan Rehabilitasi Medik, Fakultas Kedokteran Universitas Indonesia/Rumah Sakit Dr. Cipto Mangunkusumo.

Kitaoka HB, "Effect of Foot Orthose on 3- dimensional kinematics of flatfoot", http://www.acfaom.org/ diakses 15 april 2016.

Knudson, D. 2007. Fundamentals of Biomechanics. Springer Science.Second Edition.USA.

Lendra , Made Dody. 2007. Pengaruh antara Kondisi Kaki Datar dan Kaki dengan Arkus Normal terhadap Keseimbangan Statis pada Anak Berusia 8-12 Tahun di Kelurahan Karangasem Surakarta [Skripsi]. Surakarta :

Lutfie, Syarief Hasan. 2007. Hubungan antara Derajat Lengkung Kaki dengan Tingkat Kemampuan Endurans pada Calon Jemaah Haji. [Hasil Penelitian]. Jakarta: Fakultas Kedokteran dan Ilmu Kesehatan, UIN (Universitas Negeri Islam) Syarif Hidayatullah. 
Miller, Casey. 2010. What type of shoes do you wear?, (Online), (http://www.mysanantonio.com /casemymiller/ diakses 28 januari 2016).

Mineo, Michael, et al. 2004. Flexible Flatfoot. Texas: American College of Foot and Ankle Surgeons.

Mochamad Sajoto. 1988. Pembinaan Kondisi Fisik dalam Olahraga. Jakarta: Departemen Pendidikan dan Kebudayaan Direktorat Jenderal Pendidikan Tinggi Proyek Pengembangan Lembaga Pendidikan Tenaga Kependidikan.

Permana, Dhias Fajar. 2013. Perkembangan Keseimbangan pada Anak Usia 7 s/d 12 Tahun Ditinjau dari Jenis Kelamin. Jurnal Media Ilmu Keolahragaan Indonesia.

Pfeiffer, Martin., et al. 2006. Prevalence of Pes planusin Preschool-Aged Children. Journal of The American Academy of Pediatrics: Illinois.

Pohl , Michael B dan Farr, Lindsay. 2010. A Comparison of Foot Arch Measurement Reliability Using Both Digital Photography and Calliper Methods. Journal of Foot and Ankle Research: BioMed Central, (Online), (http://www.jfootankleres.com/co ntent/3/1/14/ diakses 1 februari 2016).

Prodi S1 Ortotik prostetik Unhas. 2016.

Buku Pedoman Penulisan Skripsi. Makassar:Prodi S1 Ortotik prostetik, Fakultas Kedokteran Universitas Hasanuddin.
Riemann, B.L. \& Lephart, S.M, 2002a. The sensorimotor system, part I: the physiologic basis of functional joint stability. Journal of Athletic Training,37(1); 71-79.

Santoso, Denny. 2011. Perawatan Tepat Bagi Anda yang Memiliki Telapak Kaki Datar (Flat Feet), Sport

InjuriesRehabilitation,(Online),( http://www.duniafitnes.com/sport -injuries-rehabilitation/perawatantepat-bagi-anda-yang-memilikitelapak-kaki-datar-flat-feet.html/ diakses 3 Februari 2016).

Sharma, Krishna Nand, et al. 2005. Flat Feet : A Study of 297 School Children. Tamanna Institute of Allied Health Science Allahabad: Apocon.

Shier D, Butler, J., \& Lewis, R, 2004. Somatic and Special Senses. Hole's Human Anatomy and physiology. 10th ed. New York: The McGraw-Hill Companies, Inc. 421-466.

Sujiono, Bambang.dkk, 2007, Metode Pengembangan Fisik. Jakarta: Universitas Terbuka.

Takehiro, I. 2009. Relationships Between Test Characteristics And Movement Patterns Physical Fitness, And Measurement Characteristics: Suggestions For Developing New Test Items For 2- To 6-Year-Old Children. Human Performance Measurement Vol. 5

Tadkiroatun Musfiroh. (2008). Memilih, Menyusun, dan Menyajikan Cerita untuk Anak Usia Dini. Yogyakarta: Tiara Wacana

Toho Cholik Mutohir (2004). Perkembangan Motorik pada 
14 Jurnal Keterapian Fisik, Volume 4, No 1, Mei 2019, hlm 1-58

Masa Anak-Anak.Jakarta: Proyek Pengembangan dan Keserasian Kebijakan Olahraga, Direktorat Jenderal Olahraga, Depdikanas.

Watson M A, and Black F A, 2008. "The Human Balance System" A Complex Coordination Of Central And Peripheral Systems By The Vestibular Disorders Association.

Wilson, Matthew J. 2008. Synopsis of Causation Pes Planus. Ninewells Hospital and Medical School, Dundee.

Wilton. 2014. Balance-Beam Exercises for Milwaukee-Brace Wearers: An Adjunct to Regular Recreational and Physical-Education Activities.

Available

from

http://www.acpoc.org/library/197/ $103015 . \mathrm{asp} /$ 